\title{
CORRESPONDENCE
}

\section{Role of total lung stress on the progression of early COVID-19 pneumonia: collinearity and potential confounders}

\author{
Benjamin Neetz ${ }^{1}$ (1) Jan Meis ${ }^{2}$, Felix J. F. Herth ${ }^{1}$ and Franziska C. Trudzinski ${ }^{{ }^{*}}$ (I)
}

() 2021 The Author(s)

We read with great interest the article by Coppola and colleagues on the potential role of total lung stress in the disease progression of coronavirus disease 2019 (COVID19)-related pneumonia [1]. We thank the authors for their work and appreciate the time and effort involved in performing all measurements including the assessment of the esophageal pressure swing $\left(\Delta P_{\text {eso }}\right)$ in COVID-19 patients on non-invasive respiratory support. However, we have some comments on the statistical methods, calculation of total lung stress, and potential confounders.

The authors studied the effects of total lung stress in early COVID-19 pneumonia. The associations of various variables recorded at day 1 with patient outcome were evaluated based on univariate $p$ values. Variables with $p$ values $<0.05$ were included in a multivariable regression model. This practice, though widespread in clinical publications, is highly susceptible to bias and not very sensitive to confounding effects, particularly in small sample size studies [2].

Three variables were selected by this method: total lung stress, $\Delta P_{\text {eso }}$ and $\mathrm{FiO}_{2} / \mathrm{PaO}_{2}$ ratio. The authors claim that only total lung stress was independently associated with outcome. Since $\Delta P_{\text {eso }}$ is part of the formula for total lung stress, there is reason to believe that these variables are highly correlated. As collinearity is problematic in (generalized) linear models, we think that the study could benefit from additional sensitivity analyses presenting

*Correspondence: Franziska.trudzinski@med.uni-heidelberg.de 1 Department of Pneumology and Critical Care Medicine, Thoraxklinik, University of Heidelberg, Translational Lung Research Center Heidelberg (TLRC-H), Member of the German Center for Lung Research (DZL), Heidelberg, Germany

Full author information is available at the end of the article the results of a logistic model considering the $\mathrm{FiO}_{2} / \mathrm{PaO}_{2}$ ratio and only one of the other two variables.

In addition, the calculation of the total lung stress is subject to several assumptions that call into question the close relationship to the study outcome. The total lung stress, i.e. the maximum tension in the lung parenchyma counteracting forces applied through tidal breathing, is clinically defined as endinspiratory transalveolar pressure $\left(P_{\mathrm{el}(\mathrm{L})}\right) \cdot P_{\mathrm{el}(\mathrm{L})}$ is the transpulmonary pressure in the absence of airflow (i.e. under static conditions). The total lung stress computed by Coppola et al. includes a dynamic component (i.e. $\Delta P_{\text {aw }}-\Delta P_{\text {eso }}$ ). This leads to an overestimation of the $P_{\mathrm{el}(\mathrm{L})}$ [3]. Seven patients with negative outcome had "abdominal respiratory mechanics". Recruitment of the expiratory muscles rises end-expiratory esophageal pressure. This elevates the measured $\Delta P_{\text {eso }}$ which in turn could make the computed lung stress appear higher than it actually was.

The authors considered positive end-expiratory pressure (PEEP) to be mandatory included into the total lung stress formula. But a recent study showed a significant reduction in intubation rate with higher PEEP (continuous positive airway pressure) compared to low PEEP (nasal high flow) suggesting a rather protective effect of PEEP induced lung stress [4].

In our opinion, these points underline the importance of searching for unmeasured confounding. It seems conceivable that disease severity correlates with increased pulmonary vascular thrombosis and correspondingly increased physiological dead space [5]. This would increase the ventilatory equivalent for $\mathrm{CO}_{2}$ and be associated with an increased $\Delta P_{\text {eso }}$. It would, therefore, interesting to include d-dimers as surrogate parameter as well as other established confounders such as age, obesity or cardiovascular diseases in the analysis, though the potential 
for overly exhaustive exploratory analysis is limited by the given sample size.

\section{Author details}

1 Department of Pneumology and Critical Care Medicine, Thoraxklinik, University of Heidelberg, Translational Lung Research Center Heidelberg (TLRC-H), Member of the German Center for Lung Research (DZL), Heidelberg, Germany.

${ }^{2}$ Institute of Medical Biometry, University of Heidelberg, Heidelberg, Germany.

\section{Funding}

Open Access funding enabled and organized by Projekt DEAL.

\section{Declarations}

\section{Conflicts of interest}

The authors declare to have no conflicts of interest.

\section{Research involving human participants and/or animals}

The study did not involve human or animals.

\section{Open Access}

This article is licensed under a Creative Commons Attribution-NonCommercial 4.0 International License, which permits any non-commercial use, sharing, adaptation, distribution and reproduction in any medium or format, as long as you give appropriate credit to the original author(s) and the source, provide a link to the Creative Commons licence, and indicate if changes were made. The images or other third party material in this article are included in the article's Creative Commons licence, unless indicated otherwise in a credit line to the material. If material is not included in the article's Creative Commons licence and your intended use is not permitted by statutory regulation or exceeds the permitted use, you will need to obtain permission directly from the copyright holder. To view a copy of this licence, visit http://creativecommons.org/licen ses/by-nc/4.0/.

\section{Publisher's Note}

Springer Nature remains neutral with regard to jurisdictional claims in published maps and institutional affiliations.

Accepted: 12 October 2021

Published online: 27 October 2021

\section{References}

1. Coppola S, Chiumello D, Busana M et al (2021) Role of total lung stress on the progression of early COVID-19 pneumonia. Intensive Care Med 47(10):1130-1139. https://doi.org/10.1007/s00134-021-06519-7

2. Vacheron C-H, Friggeri A, Allaouchiche B, Maucort-Boulch D, Coz E (2021) Quiet scandal: variable selection in three major intensive care medicine journals. Intensive Care Med. https://doi.org/10.1007/ s00134-021-06535-7

3. Yoshida T, Amato MBP, Kavanagh BP (2018) Understanding spontaneous vs. ventilator breaths: impact and monitoring. Intensive Care Med 44(12):2235-2238. https://doi.org/10.1007/s00134-018-5145-5

4. Perkins GD, Ji C, Connolly BA et al (2021) An adaptive randomized controlled trial of non-invasive respiratory strategies in acute respiratory failure patients with COVID-19. medRxiv preprint. https://doi.org/10. 1101/2021.08.02.21261379v1

5. Grasselli G, Tonetti T, Protti A et al (2020) Pathophysiology of COVID-19-associated acute respiratory distress syndrome: a multicentre prospective observational study. Lancet Respir Med 8(12):1201-1208. https://doi.org/ 10.1016/S2213-2600(20)30370-2 